\title{
Pattern of superficial venous arrangement in cubital fossa among preclinical Nepalese MBBS students at Birat Medical College Teaching Hospital
}

\author{
Sanjib Kumar Sah', Sidarth Timsinha ${ }^{2}$, Raju Kumar Chaudhary ${ }^{3}$, Rajesh Kumar Shah", \\ Umesh Kumar Mehta ${ }^{5}$
}

${ }^{1}$ Lecturer, ${ }^{3,5}$ Assistant Professor, Department of Anatomy, Birat Medical College Teaching Hospital, ${ }^{2}$ Associate Professor, ${ }^{4}$ Lecturer, Department of Forensic Medicine, Birat Medical College Teaching Hospital

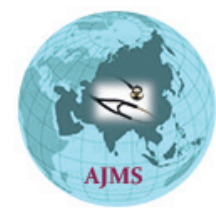

A B S TR A C T

Background: The superficial veins of the cubital fossa are frequently variable in existence and arrangement. Many clinical procedures, such as reconstructive microsurgery and arterial bypass surgery, as well as intravenous injections or therapy, require the use of superficial veins. Aims and Objective: The aim of the study was to observe and describe the variations in anatomical distribution of the superficial veins of the cubital fossa in Nepalese pre-clinical medical students. Materials and Methods: The cross-sectional study included a total of 98 students between 18 to 24 years of age. A total of 196 anterior aspects of both arms were examined for cubital venous pattern. A tourniquet was applied at the mid-arm and drawing of the pattern of veins was made on a separate unglazed paper. The venous patterns in the cubital fossa were then categorized based on their gender. Results: Six patterns of superficial veins of the cubital fossa were observed. The commonest pattern in both genders was type I pattern. No statistical significant difference was observed between patterns of superficial veins on the right and left cubital fossa ( $P=0.728$ and 0.825 respectively) in both male and female subjects. Conclusion: Our research showed six venous patterns of superficial veins at the cubital fossa in Nepalese population. Understanding the common anatomy, patterns and variations of superficial vein anastomosis is imperative as this knowledge would help those needing venous access for various medical procedures.

Key words: Cubital fossa; Gender; Nepalese; Patterns; Superficial veins

\section{Access this article online}

Website:

http://nepjol.info/index.php/AJMS DOI: $10.3126 /$ ajms.v12i10.39248

E-ISSN: 2091-0576

P-ISSN: $2467-9100$

Copyright (c) 2021 Asian Journal of Medical Sciences

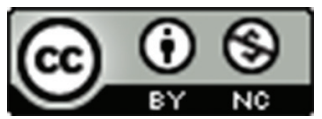

This work is licensed under a Creative Commons Attribution-NonCommercial 4.0 International License.

\section{INTRODUCTION}

The superficial veins of the cubital fossa in man have been a topic of interest to anatomists, morphologists and anthropologists as well, for health care professionals. ${ }^{1}$ The superficial veins consist of cephalic, basilic, median cubital and antebrachial veins along with their tributaries. ${ }^{2}$ The cephalic vein usually forms over the 'anatomical snuffbox' from the radial end of the dorsal venous arch. It curves proximally around the radial side of the forearm to gain its ventral aspect. The basilic vein starts medially in the dorsal venous network of the hand. It ascends posteromedially in the forearm, travels forwards to the anterior surface distal to the elbow, where it is joined by the median cubital vein. Superficially, the cubital fossa appears as a depression on the anterior aspect of the elbow. Deeply, it is a space anterior to the most distal part of the humerus and elbow joint that is filled with a variable amount of fat. ${ }^{3}$ The cubital fossa is a common site for venous blood sampling, transfusion, and intravenous therapy. The venous pattern in the cubital fossa varies significantly. Different patterns and percentages of occurrence of superficial cubital veins have been reported in various races ${ }^{4.7}$ with only one study in Caucasians. ${ }^{8}$ 
In an emergency, every clinical professional should know where to collect blood from the arm. The cephalic, basilic, median cubital and median antebrachial veins are frequently chosen for venipuncture (drawing blood) because of its characteristics: a thick lumen and an easily visible confirmation. These veins are commonly used because they are well supported by muscle and connective tissue, are visible, and are easy to palpate. However, relatively rare, but potentially serious complications including nerve injury and mistaken arterial punctures have been reported. ${ }^{9,10}$

Cubital veins are also used to introduce cardiac catheters from cardiac chambers to obtain blood samples and for cardio-angiography. ${ }^{11}$ To plan dialysis access in a given patient, it's essential to understand the anatomy patterns of the cubital superficial veins. ${ }^{12}$ Furthermore, in some superficial venous pattern types, arteries and nerves are located near or beneath the superficial veins and missed injections could be extremely dangerous to the underlying structures. Therefore, the anatomical characteristics of the sites at which venipuncture is performed need to be clearly understood to prevent these complications. In the event of occlusion, different patterns can provide collateral venous pathways. Because of the variability and clinical significance of superficial veins of the cubital fossa, this study was conducted to identify and describe variations in the anatomical distribution of superficial veins of the cubital fossa in healthy preclinical medical students of BMCTH.

\section{MATERIALS AND METHODS}

This is a cross-sectional observational study conducted at the department of Anatomy of Birat Medical College Teaching Hospital, Morang; Nepal over a period of six months from March 2021 to July 2021. The ethical clearance certificate (Reference number: IRC-PA-104/2077-78) was obtained from the Institutional Review Committee before commencement of the study. The pattern of superficial venous arrangement in the cubital fossa was studied in 196 anterior aspects of the arms among 98 Nepalese preclinical MBBS students (118 arms in 59 males, 78 arms in 39 females). Each healthy Nepalese student between 18-24 years of age providing written consent was included in the study. Students with thick tissue layer or having any wound in the cubital region or small veins measuring (less than $1 \mathrm{~mm}$ ) and students not providing consent were excluded in this study. A Tourniquet, Skin marker/tailors chalk, A4 size unglazed sheet of paper was used as data collection tool. The superficial veins of the cubital fossa were made prominent by applying a tourniquet about $10 \mathrm{~cm}$ proximal to the crease of the elbow and by active movements of the hand. The veins were marked on the skin, and the vein pattern on the right and left sides of each subject's hand was diagrammed separately on an unglazed sheet of paper. All the drawings obtained were carefully studied and analyzed. Data collected was entered in Microsoft Office Excel 2010 and further analyzed using SPSS version 20. The chi-square test was applied to compare the significant difference between the venous arrangements of superficial veins with gender. A $p$ value $<0.05$ was considered as significant.

\section{RESULTS}

In the present study the total sample consisted of 98 subjects (Males: 59; Female: 39). A total number of 196 anterior aspects of the arms (right and left) were examined for superficial venous patterns at cubital fossa. The age of the subjects ranged between 18-24 years. In our study six types of superficial venous patterns were observed (Table 1). The order of arrangement of the patterns was Type I > Type II > Type III > Type IV > Type VI > Type V. Figure 1 and 2 shows patterns of superficial veins of the cubital fossa in males and females which was observed in our study.

Table 2 shows the gender-based patterns of superficial veins in right cubital fossa. Type I pattern was the commonest pattern in both the gender found in 20(33.8\%) males and

\begin{tabular}{llc}
\multicolumn{3}{l}{ Table 1: Observation and distribution of } \\
superficial venous pattern in cubital fossa
\end{tabular}

\begin{tabular}{|c|c|c|c|c|}
\hline Type & Male & Female & Total & $P$ value \\
\hline Type I & $20(33.8 \%)$ & $18(46.1 \%)$ & $38(38.8 \%)$ & 0.728 \\
\hline Type II & $18(30.5 \%)$ & $12(30.8 \%)$ & $30(30.6 \%)$ & \\
\hline Type III & $9(15.3 \%)$ & $5(12.8 \%)$ & $14(14.3 \%)$ & \\
\hline Type IV & $5(8.5 \%)$ & $1(2.6 \%)$ & $6(6.1 \%)$ & \\
\hline Type V & $3(5.1 \%)$ & $1(2.6 \%)$ & $4(4.1 \%)$ & \\
\hline Type VI & $4(6.8 \%)$ & $2(5.1 \%)$ & $6(6.1 \%)$ & \\
\hline Total & 59 & 39 & 98 & \\
\hline
\end{tabular}




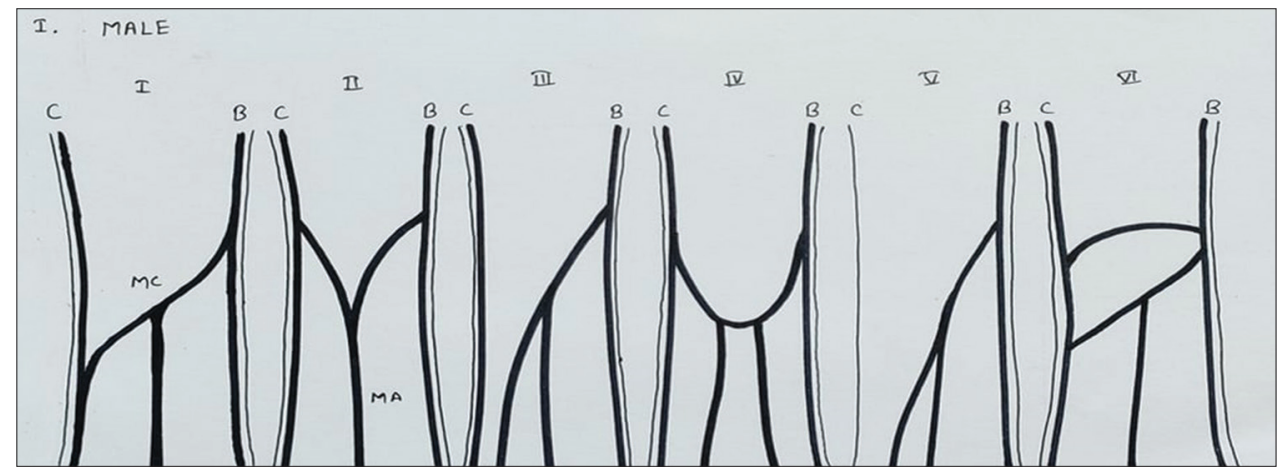

Figure 1: Showing patterns of superficial veins of the cubital fossa in males. $C=C$ Cephalic vein, $B=$ basilic vein, $M=$ median cubital vein, $M=$ median antebrachial vein.

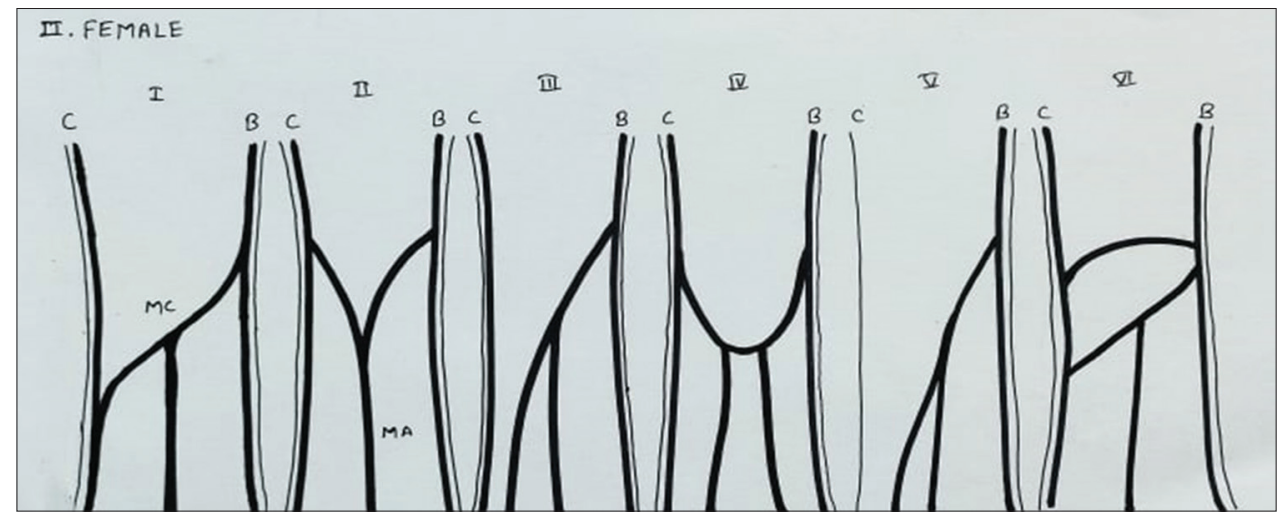

Figure 2: Showing patterns of superficial veins of the cubital fossa in females. $C=$ Cephalic vein, $B=$ basilic vein, $M=$ median cubital vein, $M=$ median antebrachial vein.

18(46.1\%) females respectively. Type II pattern was the second most common pattern consisting of $18(30.5 \%)$ in males and $12(30.8 \%)$ in females. However, the other patterns (type IV, V and VI) were recorded below 10\% in both genders. Using Pearson Chi-Square test, there was no statistical significant difference between patterns of superficial veins on the right cubital fossa and gender. $\mathrm{P}=0.728$

Table 3 shows the type I pattern was also the most common pattern in the left cubital fossa, with $20(33.8 \%)$ and 16 (41\%), respectively, in males and females. Type II pattern was the second most common pattern occurring in $18(30.5 \%)$ of males and $12(30.8 \%)$ of females. Type III pattern was seen in $9(15.3 \%)$ of males and $7(17.9 \%)$ females. Type IV, V and VI venous patterns were found in small percentage ranging from $2.6 \%$ to $6.8 \%$. There was no statistically significant difference in patterns of superficial veins of left cubital fossa and gender $(\mathrm{P}=0.825)$.

\section{DISCUSSION}

In this study, six patterns of superficial venous patterns of cubital fossa were observed. Type 1 pattern in which the median cubital vein crossing from cephalic to basilic

\begin{tabular}{lcccc}
\multicolumn{5}{l}{ Table 3: Gender distribution of superficial } \\
venous pattern of left cubital fossa \\
\hline Type & Male & Female & Total & P value \\
\hline Type I & $20(33.8 \%)$ & $16(41 \%)$ & $36(36.7 \%)$ & 0.825 \\
Type II & $18(30.5 \%)$ & $12(30.8 \%)$ & $30(30.6 \%)$ & \\
Type III & $9(15.3 \%)$ & $7(17.9 \%)$ & $16(16.3 \%)$ & \\
Type IV & $4(6.8 \%)$ & $1(2.6 \%)$ & $5(5.1 \%)$ & \\
Type V & $4(6.8 \%)$ & $1(2.6 \%)$ & $5(5.1 \%)$ & \\
Type VI & $4(6.8 \%)$ & $2(5.1 \%)$ & $6(6.1 \%)$ & \\
Total & 59 & 39 & 98 & \\
\hline
\end{tabular}

vein was the most common pattern in both genders. The incidence of occurrence of this pattern in males was $(33.9 \%)$ and in females was $(43.6 \%)$. Different patterns of superficial cubital veins and percentages of occurrence have been reported in various races. This pattern was present in $(62.4 \%)$ of males and $(78.8 \%)$ of females. ${ }^{13}$ The percentage of this pattern was higher compared to our study. A study on three major ethnicities in Malays, Chinese and Indians this pattern was found in 34\% males and $32.5 \%$ females. ${ }^{14}$ The second common pattern in our study was Type II pattern in which the medial ante brachial vein branching in two in the cubital fossa ending in basilic and cephalic vein. The incidence of occurrence of this pattern was almost even in both genders accounting 30.5 
$\%$ in males and $30.8 \%$ in females. This figure differs from the percentage found in an Iraqi study, which found this pattern in $59.7 \%$ of males and $48.5 \%$ of females. The percentage of this pattern was quite higher as compared to our study. ${ }^{15}$ This pattern was also observed as the second most common pattern by Dharap AS et al., ${ }^{13}$ seen in $18.8 \%$ of males and $11.5 \%$ females. A Jordanian study ${ }^{16}$ observed similar findings of this pattern in $18.2 \%$ of males and $16.6 \%$ of females. The percentages of this pattern were quite low in comparison to our study. The third common pattern in our study was that the median vein does not join the cephalic and the basilic veins i.e., Type III. The occurrence of this pattern was observed in $15.3 \%$ of both sexes. Dharap et al., ${ }^{13}$ identified this pattern in $8.8 \%$ of males and $7.3 \%$ of females. The incidence of this pattern was reported by Wasafi et al., ${ }^{15}$ in $16.5 \%$ of males and 11 $\%$ of females. The Type IV pattern was the cephalic vein and basilic vein connected by an arching vein proximally, accounting for $5.1 \%$ of the total. The lower percentage of this pattern is comparable to $4 \%$ in a Nigerian and 4.5 $\%$ in a Malaysian study. ${ }^{6,14}$ The fifth pattern was that only presence of the basilic vein present in $5.9 \%$ of males and $2.6 \%$ of females. In Malays this pattern was seen in $2.9 \%$ males and $1.0 \%$ females which is lower than the percentage found in the current study. ${ }^{12}$ In Jordanians this pattern was found in $5.3 \%$ males and $13.6 \%$ females. ${ }^{16}$ The sixth pattern was that in which median cubital veins join the cephalic and basilic veins found in 5.9\% in both sexes. In a Malay study, however, this pattern was seen in only one male subject $(0.6 \%)$ and none of the females. ${ }^{13}$ In adult Jordanians it was observed in two male subjects $(1.5 \%)$ but none in females. ${ }^{16}$ As shown in our study, there was no statistically significant difference between superficial venous patterns of the cubital fossa and gender in any of the previous studies. ${ }^{13-16}$

\section{LIMITATIONS OF THE STUDY}

In our study, we used a non-invasive procedure to identify the various pattern of superficial cubital veins among medical students. In order to understand more about variability of cubital veins in the future, fine dissection of cadavers will be required. A better understanding of the venous pattern types in different ethnicities could help people become more aware of these unusual cubital venous patterns, as well as perform safer medical procedures.

\section{CONCLUSION}

Cubital venous patterns vary in number and frequency across populations, as evidenced by our research. Understanding the common anatomy and patterns of superficial vein anastomosis at the cubital fossa is vital.
Many medical procedures like venous blood sampling, transfusion, infusion, intravenous therapy, placement of dialysis access would benefit from understanding the variations of superficial veins at cubital fossa. In our research, we discovered six different types of superficial venous patterns. The type I pattern was the most common pattern in males and females followed by type II pattern. There was no significant difference in the patterns of superficial veins in the cubital fossa when compared with gender.

\section{ACKNOWLEDGEMENT}

We would like to thank all of the participants from Birat Medical College Teaching Hospital for their active participation in the study, as well as the supporting staff of Department of Anatomy for their assistance with the research.

\section{REFERENCES}

1. Standring, S. Gray's anatomy, $41^{\text {st }}$ ed. Edinburg: Elsevier Churchill Livingstone, 2016.

2. Williams PL, Bannister LH, Berry MM, Collins P, Dyson M, Dussek JE. et al. Gray's Anatomy. $38^{\text {th }}$ ed. Edinburgh UK: Churchill Livingstone; 1995.

3. Moore KL, Dalley AF. Clinically Oriented Anatomy. 5 th ed. Baltimore, MD: Lippincott Williams; 2006.

4. Berry RJ, Newton HA. A study of the superficial veins of the superior extremity in 300 living subjects. Anat Anz. 1908; 33: 591-601.

5. Charles CM. On the arrangement of the superficial veins of the cubital fossa in American white and American negro males. Anat Rec. 1932; 54: 9-4. https://doi.org/10.1002/ar.1090540103

6. Singh JD. Patterns of superficial veins of the cubital fossa in Nigerian subjects. Acta Anat (Basel). 1982;112(3):217-9 https://doi.org/10.1159/000145513

7. Tewary SP, Singh SP, Shamer S The arrangement of superficial veins in the cubital fossa in Indian subjects. J Anat Soc. 1971; 20: 99-102.

8. Vučinić N, Erić M, Macanović M. Patterns of superficial veins of the middle upper extremity in Caucasian population. J Vasc Access. 2016;17(1):87-92.

https://doi.org/10.5301/jva.5000429

9. Newman BH, Waxman DA. Blood donation-related neurologic needle injury: evaluation of 2 years' worth of data from a large blood center. Transfusion. 1996; 36(3):213-215. https://doi.org/10.1046/j.1537-2995.1996.36396182137.x

10. Kato J, Araki H, Kimura M, Takahashi K, Ueda K, Lida R. Incidence and prognosis of persistent pain induced by venipuncture for blood sampling: an observational study over a 5-year period. Pain Med. 2012; 13(12):1627-1630. https://doi.org/10.1111/j.1526-4637.2012.01490.x

11. Lee H, Lee $\mathrm{SH}$, Kim SJ, et al. Variations of the cubital superficial vein investigated by using the intravenous illuminator. Anatomy \& Cell Biology. 2015; 48(1):62-65.

https://doi.org/10.5115/acb.2015.48.1.62 
12. Snell RS. Clinical anatomy by regions., $9^{\text {th }}$ ed. Baltimore: Lippincott Williams \& Wilkins; 2012.

13. Dharap AS, Shaharuddin MY. Patterns of superficial veins of the cubital fossa in Malays. Med J Malaysia. 1994; 49(3): 239-241.

14. Hamzah AA, Ramasamy S, Adnan AS, Khan AH. Pattern of Superficial Venous of the Cubital Fossa among Volunteers in a Tertiary Hospital. Trop Med Surg. 2014; 2(2): 164.

https://doi.org/10.4172/2329-9088.1000164
15. Wasfi FA, Dabbagh AW, AIAthari FM, Salman SS. Biostatistical study on the arrangement of the superficial veins of the cubital fossa in Iraqis. Acta Anat (Basel). 1986; 126: 183-186. https://doi.org/10.1159/000146212

16. AlBustami F, Altarawneh I, Rababah E. Pattern of Superficial Venous Arrangement in the Cubital Fossa of Adult Jordanians. J Med J. 2014; 48 (4):269- 274.

https://doi.org/10.12816/0025077

Author's Contribution:

SKS-Concept and design of the study, prepared first draft of manuscript, preparation of manuscript, interpretation of the results; ST-Reviewed the literature,

statistical analysis and revision of the manuscript; RKC-Concept, coordination and data compilation; RKS-Data acquisition; UKM- reviewed the literature.

Work Attributed to:

Birat Medical College Teaching Hospital, Morang, Nepal.

ORCID ID:

Dr Sanjib Kumar Sah- (1) https://orcid.org/0000-0001-8361-5497

Dr Sidarth Timsinha- (D) https://orcid org/0000-0003-3707-3855

Raju Kumar Chaudhary- io https://orcid.org/0000-0002-7636-3356

Rajesh Kumar Shah- https://orcid.org/0000-0002-4207-8709

Umesh Kumar Mehta- (D) https://orcid.org/0000-0003-3095-8415

Source of Funding: None, Conflict of Interest: None. 